\title{
Time-dependent Yield Moment Model for Deteriorated Steel Connections
}

\author{
Bin $\mathrm{HU}$ \\ School of Engineering \\ RMIT University \\ Melbourne, Australia \\ e-mail: s3411763@student.rmit.edu.au
}

\author{
Ricky WK CHAN \\ School of Engineering \\ RMIT University \\ Melbourne, Australia \\ e-mail: ricky.chan@rmit.edu.au
}

\begin{abstract}
Steel structural connections are integral parts in steel structures. They are widely used in building frames to join different structural members together as well as to support gravitational load, shear load and bending moment and to transmit them to the adjacent structural components. However, gradual thinning of steel due to corrosion damage reduces their load bearing capacity, loses structural connectivity and subsequently jeopardises the structural integrity of the entire structure. This paper presents a remaining capacity assessment method, namely timedependent yield moment model, for steel structural connection derived analytically based on a time-dependent corrosion rate model and yield-line theory. Time dependent yield moment model of steel structural connection is derived analytically as a function of time and geometric parameters of the plate. Solution to a wide-flange-section-to-column-baseplate connection subjected to minor axis bending moment and flush endplate beam-column connection subjected to in-plane bending moment is presented. Results of the analytical expression are compared to a three-dimensional nonlinear finite element model and good agreement is obtained. The proposed model may contribute to the prediction of remaining strength and repair schedule of corroded steel structural connections.
\end{abstract}

Keywords-steel structural connection; time-dependent yield moment model; yield line analysis; steel corrosion

\section{INTRODUCTION}

Steel structural connections (i.e. column base and beamcolumn connection) are integral parts in steel structures. They support gravity, lateral load; shear load and bending moment from the structural members as well transfer and spread the loading to the adjacent structural components. Steel structural connections are one of the most structurally critical components of the entire structure because its failure may result in a catastrophic collapse of a structure if the connections no longer meet the safe structural criteria. However, steel is vulnerable to corrosion, which gradually reduces the thickness of the material, and decreases structural strengths. For instance, a $4 \mathrm{~m}$ high steel light pole in Sydney, Australia toppled onto the footpath without any warning and it was later found rust and discolorations in the base of the pole. Fortunately, no injury was caused [1]. Therefore, it is necessary to develop a method to predict the remaining structural strength of steel structural connections that are exposed in the corrosive environment.

For reinforced concrete structures, corrosion occurs in the embedded reinforcements and methods to evaluate and its time dependent structural deterioration model was developed [2]. For steel structures, structural capacities (e.g. flexural, shear, bearing and lateral torsional bulking strength) of corroded I-beams were proposed [3, 4]. The remaining thickness of rusted I-beams is estimated in order to establish thickness reduction patterns of I-beam. Based on the damage pattern, the remaining structural capacities are predicted [3]. However, most of the corrosion deterioration models were developed for structural members such as beams and columns, very few studies were developed for column base and beam-column connections [5].

This paper proposes a new analytical model to predict the corrosion-induced deteriorating moment capacity of steel structural connection. The model is based on a power function deterioration model of steel in conjunction with yield lines formed on steel plates. To illustrate the concept, a base consists of a wide-flange column with a welded baseplate and two anchor bolts as well as a flush endplate beam-column connection are presented. The new model is compared with a non-linear three-dimensional finite element model. For different exposure category, this time-dependent model may predict the strength steel structural connection.

\section{YIELD LINE THEORY}

Yield line theory was developed by Johansen [6] and originally applied to the calculation of the collapse load or yield moment of reinforced concrete slabs. The theory can also be analogously employed to the plastic capacity prediction of steel plate and steel connections, which has been extensively applied [7-10]. Yield line is a straight or curve line located at the plastically failed zone of the structural elements characterized by continuously formed plastic hinges. Most of the yield-line patterns are derived by the experimental observation. In addition, the plastic strain localisation derived from computer simulation is compared with the deformed specimen derived from experiment, and it was attested that the strain distribution from FE analysis is able to situate the yield lines [11].

Generally there are two methods to carry out yield line analysis, namely the equilibrium strip method and energy method (also called virtual work method) [12, 13]. The latter solution is a more popular and widely adopted, as it is relatively straightforward particular for more complex geometries. In principle, the external work done by the 
applied force or moment (1) is equated to internal virtual work (2) stored in the yield line.

$$
\mathrm{W}_{\mathrm{e}}=\mathrm{M}_{\mathrm{y}} \theta_{\mathrm{e}} \text { or } \mathrm{W}_{\mathrm{e}}=\mathrm{F}_{\mathrm{f}} \Delta \text {, }
$$

where $M_{y}$ is the yield moment of the structure and $\theta$ is the virtual rotation induced by the moment $M_{y} . F_{f}$ is the applied failure load in the structure and $\Delta$ is the arbitrary virtual deflection of the deformed structure.

$$
\mathrm{W}_{\mathrm{i}}=\int_{\mathrm{L}_{\mathrm{n}}} \mathrm{m}_{\mathrm{p}} \theta_{\mathrm{n}} \mathrm{ds}=\sum_{\mathrm{n}=1}^{\mathrm{N}} \mathrm{m}_{\mathrm{p}} \theta_{\mathrm{n}} \mathrm{L}_{\mathrm{n}}
$$

where $\theta_{n}$ is the plastic rotation at the $n^{\text {th }}$ yield line, $L_{n}$ is the length of the $n^{\text {th }}$ yield line and $m_{p}$ is the plastic moment capacity per unit length of the structure as follows:

$$
\mathrm{m}_{\mathrm{p}}=\frac{\mathrm{f}_{\mathrm{y}} \mathrm{t}_{\mathrm{p}}^{2}}{4}
$$

Here $f_{y}$ is the yield stress of the material and $t_{p}$ is the plate thickness. At equilibrium, the flexural strength of the plate structure can be analytically expressed as

$$
\mathrm{M}_{\mathrm{y}}=\sum_{\mathrm{n}=1}^{\mathrm{N}} \mathrm{m}_{\mathrm{p}} \theta_{\mathrm{n}} \mathrm{L}_{\mathrm{n}} / \theta_{\mathrm{e}}
$$

\section{CORROSION RATE}

Corrosion rates of steel from various outdoor environments (i.e. rural, urban and marine environment) were extensively studied [14, 15]. A power function is derived from 8 years of atmospheric corrosion tests of weathering steel and carbon steel under different exposure environment, as described in (5).

$$
d(t)=A \times t^{B}
$$

where $d(t)$ is corrosion wastage depth (in $\mu \mathrm{m}$ ) after $t$ years of exposure time. $A$ is the initial corrosion loss at the unity time (i.e. the corrosion penetration after the first year of exposure). $B$ is the corrosion rate under the long-term exposure. Parameters $A$ and $B$ are typically determined by regression analysis of the measured data.

TABLE I.

\section{CORROSION RATE MODEl PARAMETERS}

\begin{tabular}{|c|c|c|}
\hline \multirow{2}{*}{ Environment Type } & \multicolumn{2}{|c|}{ Carbon Steel } \\
\cline { 2 - 3 } & $\boldsymbol{A}$ & $\boldsymbol{B}$ \\
\hline Rural & 34 & 0.65 \\
\hline Urban & 80.2 & 0.59 \\
\hline Marine & 70.6 & 0.79 \\
\hline
\end{tabular}

Although other corrosion models are available, this power corrosion rate function is simple and thus most commonly used in literatures $[14,16]$. Suggested values of parameters $A$ and $B$ are given in Table I [15].

\section{PROPOSED TIME-DEPEDENT YIELD MOMENT MODEL}

For bolted steel connections, failures usually occur at locations where yielding and excessive deformation occur. Stresses tend to concentrate around bolt holes and yield lines due to prying action. Based on the yield line theory and power corrosion rate model, an analytical solution, which is time-dependent yield moment model (TDYMM), is formulated as below:

$$
M_{y}(t)=\sum_{n=1}^{N} f_{y}\left(t_{p}-A \times t^{B}\right)^{2} \theta_{n} L_{n} / 4 \theta_{e}
$$

The calculation of (6) is based on the prediction of yield line pattern on the deformed plate(s) to determine the geometrical factors (i.e. $\theta_{\mathrm{n}}, \mathrm{L}_{\mathrm{n}}$ and $\theta_{\mathrm{e}}$ ) as well as the environmental corrosivity factors (i.e. $A$ and $B$ ).

\section{A. Column Base}

Fig. 1 presents the assumed yield lines pattern on column baseplate upon bending with respect to column's weak axis. Dimensions required to define the yield lines are also annotated. Based on (2), the virtual work is presented in (7). Equating the external work and virtual internal work, the yield moment of the column base can be expressed as (8). And the TDYMM for the selected column base is formulated as (9)

$$
\begin{aligned}
& W_{i}=2 m_{p} \Delta\left[\frac{a}{c}+\frac{a}{g}+\frac{a+b}{c}+2 \pi\left(\frac{g-j-d}{g}\right)+\frac{(g-j)}{g} \frac{\left(k^{2}+j^{2}\right)}{k j}+\frac{d^{2}}{g f}\right](7) \\
& m_{d}=\frac{f_{y} T_{b p}^{2}}{2} \times c \times\left[\frac{a}{c}+\frac{a}{g}+\frac{a+b}{c}+2 \pi\left(\frac{g-j-d}{g}\right)+\frac{(g-j)}{g} \frac{\left(k^{2}+j^{2}\right)}{k j}+\frac{d^{2}}{g f}\right](8) \\
& m_{y}(t)=\frac{c f_{y}\left(T_{b p}-A t^{D}\right)^{4}}{2}\left[\frac{a}{c}+\frac{a}{g}+\frac{a+b}{c}+2 \pi\left(\frac{g-j-d}{g}\right)+\frac{(g-j)}{g} \frac{\left(k^{2}+j^{2}\right)}{k j}+\frac{d^{2}}{g f}\right](9)
\end{aligned}
$$

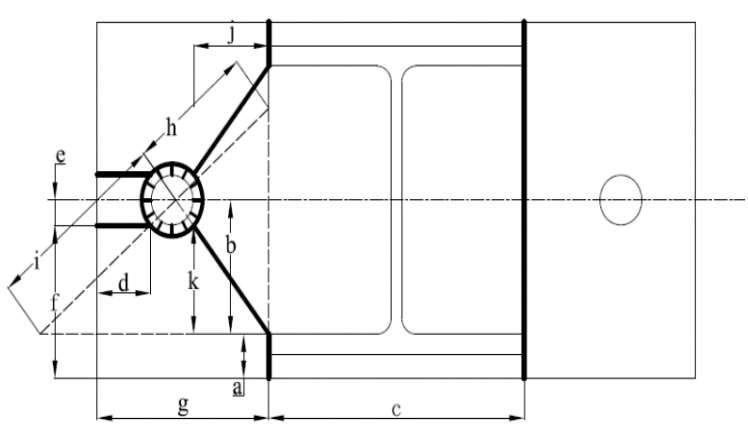

Figure 1. Yield line pattern on base plate 


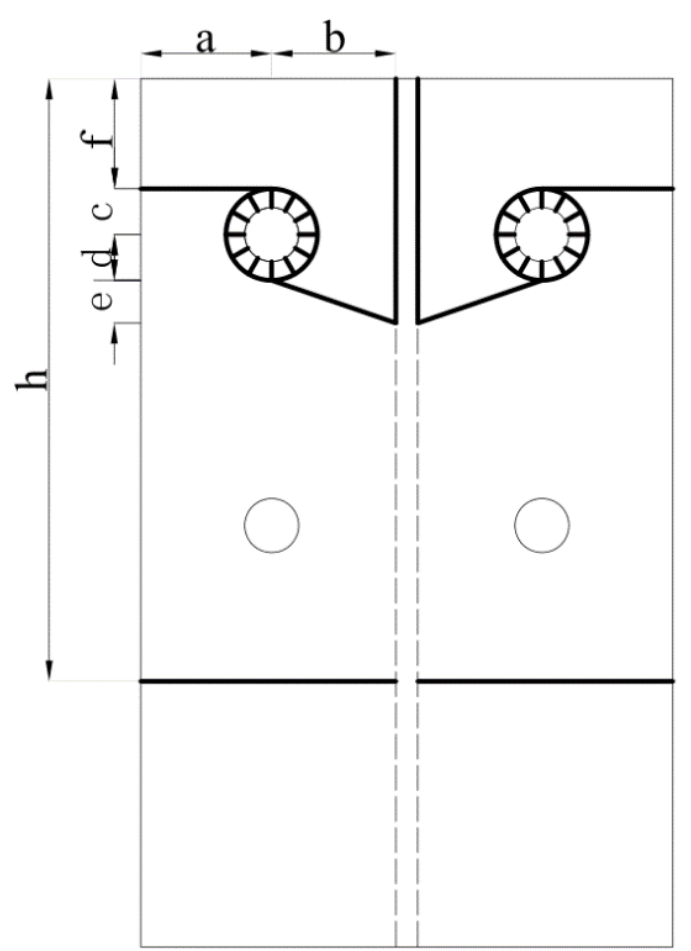

Figure 2. Yield line pattern on column flange

\section{B. Beam-column Joint}

Fig.2 presents the assumed yield lines pattern on the column flange which is jointed to a beam by flush endplate connection. Dimensions required to define the yield lines are also annotated. Based on (2), the virtual work is presented in (19). Equating the external work and virtual internal work, the yield moment of the beam-column connection can be expressed as (11). And the TDYMM for the selected column base is formulated as (12)

$$
\begin{aligned}
& \mathrm{W}_{\mathrm{i}}=2 \mathrm{hm}_{\mathrm{p}} \Delta\left[\frac{a}{c+d}+\frac{a}{f}+\frac{e}{b}+\frac{b}{e}+\frac{h}{a+b}+\frac{a+b}{h-e}+4 \pi \frac{c+d}{h}\right] \\
& \mathrm{m}_{\mathrm{u}}=\frac{\mathrm{f}_{y} \mathrm{~T}_{\mathrm{f}}^{2}}{2} \mathrm{~h}\left(\frac{\mathrm{a}}{\mathrm{c}+\mathrm{d}}+\frac{\mathrm{a}}{\mathrm{f}}+\frac{\mathrm{e}}{\mathrm{b}}+\frac{\mathrm{b}}{\mathrm{e}}+\frac{\mathrm{h}}{\mathrm{a}+\mathrm{b}}+\frac{\mathrm{a}+\mathrm{b}}{\mathrm{h}-\mathrm{e}}+4 \pi \frac{\mathrm{c}+\mathrm{d}}{\mathrm{h}}\right) \\
& \mathrm{m}_{\mathrm{y}}(\mathrm{t})=\frac{\mathrm{f}_{\mathrm{y}}\left(\mathrm{T}_{\mathrm{ff}}-\mathrm{At}^{\mathrm{B}}\right)^{c}}{2} \mathrm{~h}\left(\frac{\mathrm{a}}{\mathrm{c}+\mathrm{d}}+\frac{\mathrm{a}}{\mathrm{f}}+\frac{\mathrm{e}}{\mathrm{b}}+\frac{\mathrm{b}}{\mathrm{e}}+\frac{\mathrm{h}}{\mathrm{a}+\mathrm{b}}+\frac{\mathrm{a}+\mathrm{b}}{\mathrm{h}-\mathrm{e}}+4 \pi \frac{\mathrm{c}+\mathrm{d}}{\mathrm{h}}\right)
\end{aligned}
$$

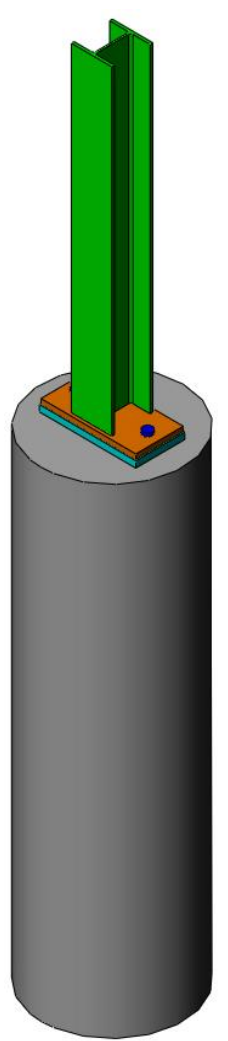

(a)

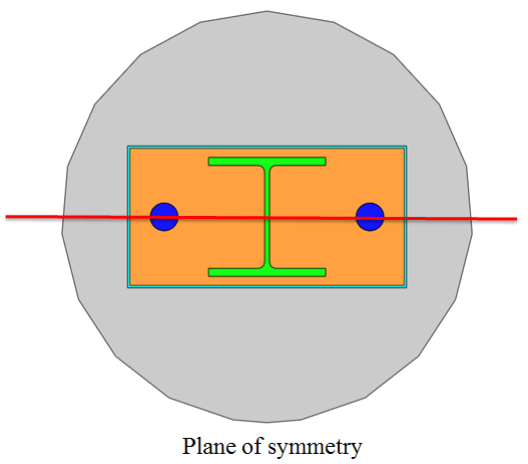

(b)
Figure 3. (a) Overall geometry, (b) plane of symmetry

\section{FINITE ELEMENT ANALYSIS}

In order to verify the proposed yield line model (8) and (11) of steel column base and beam-column connection, respectively, commercial finite element package ABAQUS $6.11[17]$ is adopted. Three-dimensional continuum hexahedral brick elements with one reduced integration point (C3D8R) are used in the entire model.

\section{A. Geometry of the Connections and Boundary Condtion}

A typical column base configuration is selected for this study, as shown as Fig.3 (a). Two anchor bolts are located along the neutral axis of column. This arrangement is typically assumed as pinned support, which is commonly used in lightly loaded portal frames and multi-storey steel frames. An Australian 250UC column [18] is fillet-welded onto a steel base plate $(300 \mathrm{~mm} \times 600 \mathrm{~mm} \times 32 \mathrm{~mm})$. Two $36 \mathrm{~mm}$ diameter anchor bolts are located along weak axis of the column with an embedded length of $1800 \mathrm{~mm}$. A $40 \mathrm{~mm}$ thick grout is filled between the baseplate and a $760 \mathrm{~mm}$ diameter cylindrical concrete foundation (3000 mm deep). For simplicity the soils around concrete base is not included. The surfaces of concrete foundation are restrained. The bolt holes in baseplate are $2 \mathrm{~mm}$ larger than the bolt shank diameter. In addition, due to symmetry of the geometry, only half of the structure is modelled to save computation effort (Fig.3b).

For the beam-column flush endplate connection, the assembly is configured in Fig 4 (a). Australian 250UC [18] 
is chosen to form the column and beam. One extremity of the beam is fillet-welded onto a steel endplate $(250 \mathrm{~mm} \mathrm{x}$ $280 \mathrm{~mm} \times 20 \mathrm{~mm}$ ). Four grade $8.8 \mathrm{M} 20$ bolts are situated at each corner of the endplate and joined the endplate to the flange of column. The bolt holes in endplate and flange of column are $2 \mathrm{~mm}$ larger than the bolt shank diameter. The bottom end of column is encastred. In order to save computation time and simplify the model, only half of the structure is modelled as it is structurally and geometrically symmetrical.

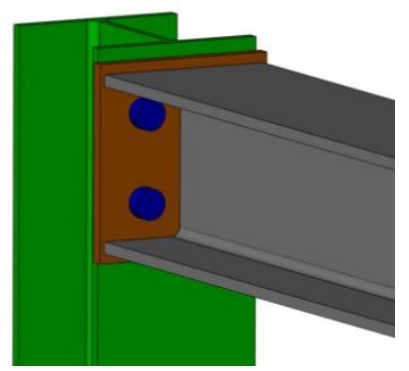

(a)

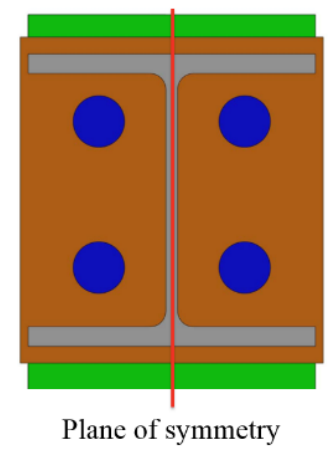

(b)
Figure 4. (a) Overall geometry, (b) plane of symmetry

\section{B. Material and Contact Properties}

Elastic-plastic material model is adopted for the steel of bolts, base plate, end plate, beam and column. The Young's Modulus is 200GPa and Poisson's ratio is 0.3. The type of steel for base plate is assumed as 300 Plus steel with 300MPa yield stress, while the category of steel for the bolts is used as Grade 8.8 with $660 \mathrm{MPa}$ yield stress. On the other hand, the layer of grout is assumed as cement mortar. Concrete has a Young's Modulus of 26GPa and Poisson's ratio is 0.2 . It is assumed the failure of the column base is happened because of the plastic bending of base plate and the concrete still remain elastic.

The surface-to-surface contact is applied to the surface interaction of (i) column base model: baseplate-bolts, baseplate-grout, grout-bolt; (ii) beam-column connection model: beam-end plate, endplate- column, bolts-column and bolts-endplate. The friction coefficient is 0.3 for the tangential behaviour and hard contact is selected for the normal behaviour. Small sliding is selected for all contact interactions. The fillet welding between base plate and column bottom end is simulated by tie constraints. The bond behaviour between the bolts and concrete footing are assumed tied. The analysis is divided by three general static steps: (i) preloading the bolts; (ii) fixing the bolt at certain length after the exertion of bolt load; (iii) applying the horizontal displacement at the top end of the column for column base model or vertical downward displacement to the end of the beam.

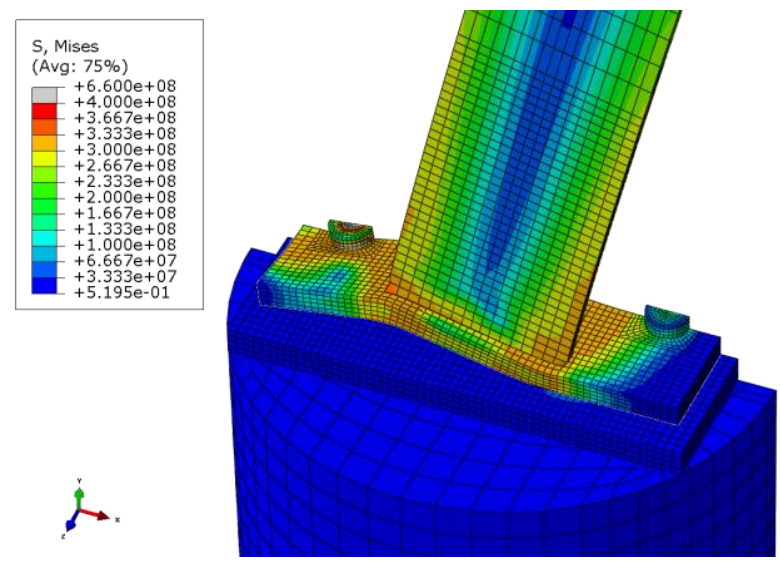

Figure 5. Moment-rotation relationship of the steel column base

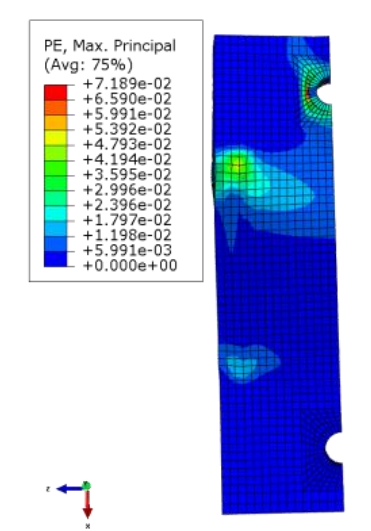

(a)

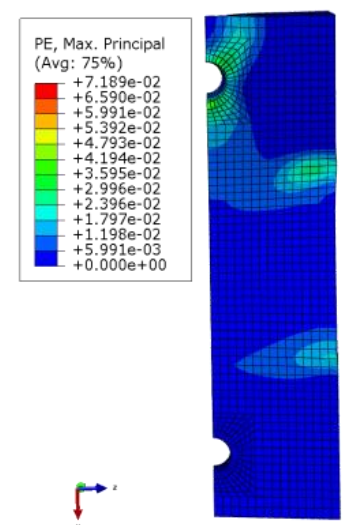

(b)
Figure 6. Strain distribution of base plate: (a) top view, (b) bottom view

$$
\text { TABLE II. PARAMETERS IN (7), (8) AND (9) }
$$

\begin{tabular}{|c|c|c|c|c|c|c|}
\hline Parameter & $\boldsymbol{a}$ & $\boldsymbol{b}$ & $\boldsymbol{c}$ & $\boldsymbol{d}$ & $\boldsymbol{e}$ & $\boldsymbol{f}$ \\
\hline Value $(\mathrm{mm})$ & 37.3 & 112.5 & 256 & 53.4 & 21.6 & 128.4 \\
\hline Parameter & $\mathbf{g}$ & $\mathbf{j}$ & $\mathbf{k}$ & $\mathbf{T}_{\mathbf{b p}}$ & \multicolumn{2}{|c|}{$\mathbf{f}_{\mathbf{y}}(\mathbf{M P a})$} \\
\hline Value $(\mathrm{mm})$ & 172 & 75.4 & 91.43 & 32 & \multicolumn{2}{|c|}{300} \\
\hline
\end{tabular}

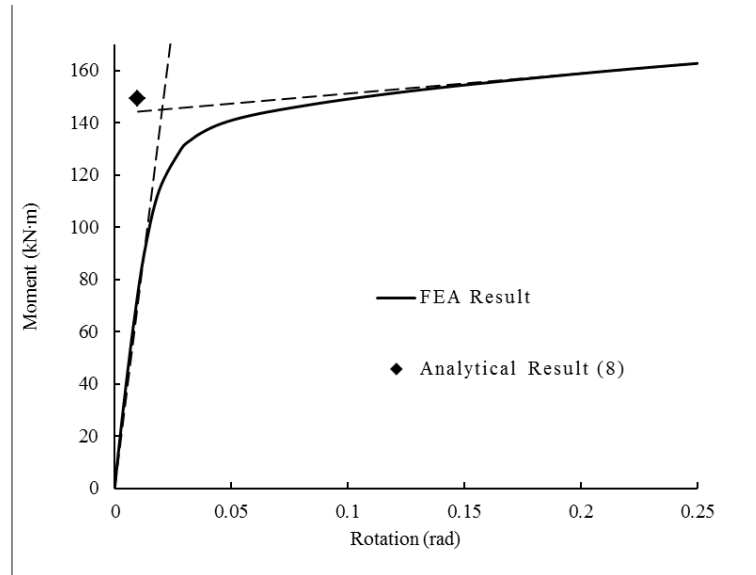

Figure 7. Stress distribution of deformed column base (Unit: MPa) 
TABLE III. COMPARISON WITH FEA AND ANALYTICAL RESUlT

\begin{tabular}{|c|c|c|c|}
\hline $\begin{array}{c}\text { Connection } \\
\text { Type }\end{array}$ & $\begin{array}{c}\text { FE yield } \\
\text { moment } \\
\text { (kNm) }\end{array}$ & $\begin{array}{c}\text { Predicted yield } \\
\text { moment } \\
\text { (kNm) }\end{array}$ & Difference \\
\hline Column base & 142.59 & 149.36 & $4.8 \%$ \\
\hline $\begin{array}{c}\text { Beam-column } \\
\text { joint }\end{array}$ & 131.32 & 119.38 & $-9.1 \%$ \\
\hline
\end{tabular}

\section{RESULT AND DISCUSSION}

\section{A. Column Base}

Fig. 5 shows the deformed shape and stress distribution of the column base. Under bending about column base's weak axis, a portion of base plate is lifted from the base under prying action. It is clear that the base plate is spreading loads from column onto a large area. In Fig.6, the strain distribution of deformed baseplate is shown. Strain is high in the bent areas of the plate and around vicinity of the bolt holes. The moment-rotation relationship obtained from FE analysis is shown in Fig.7, and the yield moment $(142.59 \mathrm{kNm})$ is determined by the intersection of the initial connection stiffness and post-yield stiffness. Also, the predicted yield moment $(149.36 \mathrm{kNm})$ derived from (8) is indicated in Fig.7. The parameters used are shown in Table II. The comparison of the FE yield moment and predicted yield moment (8) is summarised in Table III. It is clear that a good agreement is obtained.

\section{B. Beam-column Connection}

Fig.8(a) shows the deformed shape and stress distribution of selected beam-column connection. As the selected endplate $(20 \mathrm{~mm})$ is thicker than the flange of column $(17.3 \mathrm{~mm})$, the plastic yielding happens at the flange of column while the end plate (as shown in Fig 8 (b)) is in a structurally sound condition after the completion of analysis. Under bending action, a portion of column flange is arched at the location of the upper row of bolts' holes. In Fig. 9, the strain distribution of deformed flange of column is shown. Strain is high in the bent areas of the flange and around vicinity of the upper row of bolts' holes. The momentrotation relationship obtained from FE analysis is shown in Fig 5, and the yield moment $(131.32 \mathrm{kNm})$ is determined by the intersection of the initial connection stiffness and postyield stiffness. Also, the predicted yield moment $(120.56 \mathrm{kNm})$ derived from (11) is indicated in Fig 10. The parameters used are shown in Table IV. The comparison of the FE yield moment and predicted yield moment (11) is summarised in Table III. A good agreement of result comparison is obtained.

Based on the parameters in Table I, moment capacity of column bases under different exposure categories is predicted for the first 50 years, as shown in Fig. 11, and time-dependent moment capacity of beam-column connection is predicted in Fig.12. It is assumed that no corrosion protection or maintenance is carried out during their service life. Normalised moment capacity to initial value is shown. It is clear that the deterioration the marine environment is the most corrosive while the rural is gentle.
In 50 years, column base moment capacity reduces by approximately $10 \%$ under marine environment. However, the yield moment for bean-column connection is predicted to drop significantly, particularly by $20 \%$ under marine envrioment.

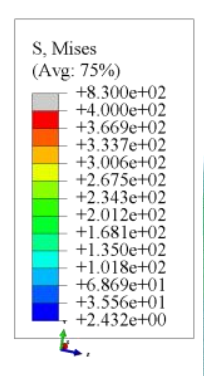

(a)

(a)

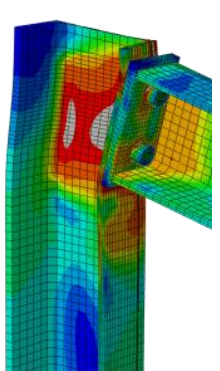

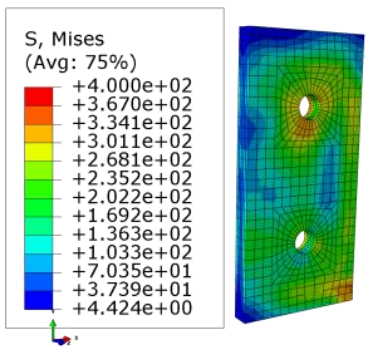

(b)
Figure 8. Stress distribution of deform beam-column connection (unit: $\mathrm{MPa})$; (b) stress distribution of end plate

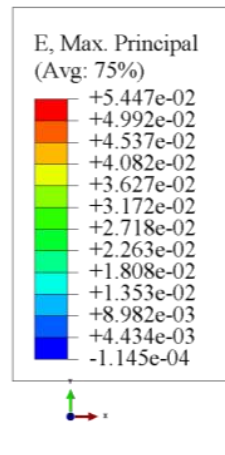

(a)

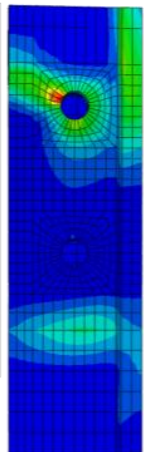

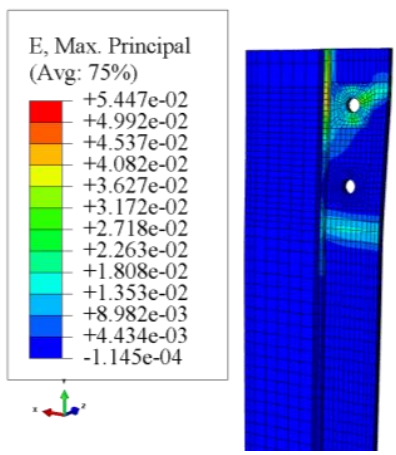

(b)
Figure 9. Strain distribution of deformed column flange

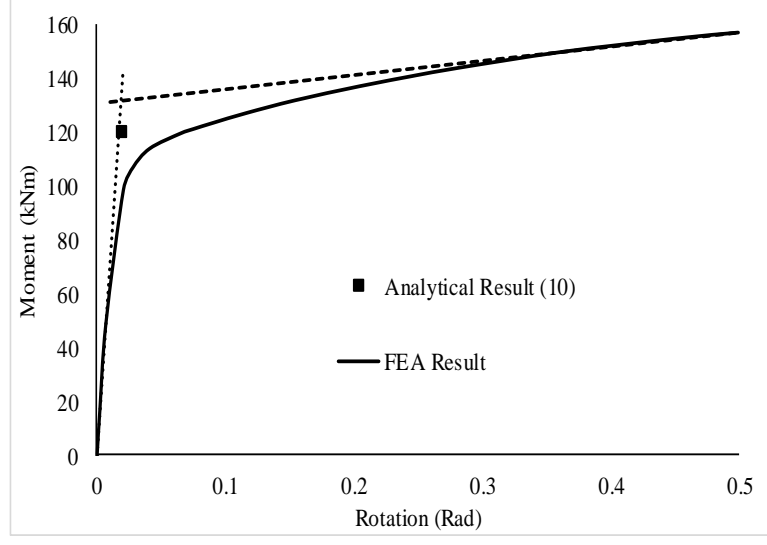

Figure 10. Moment-rotation relationship of the steel beam-column connection 


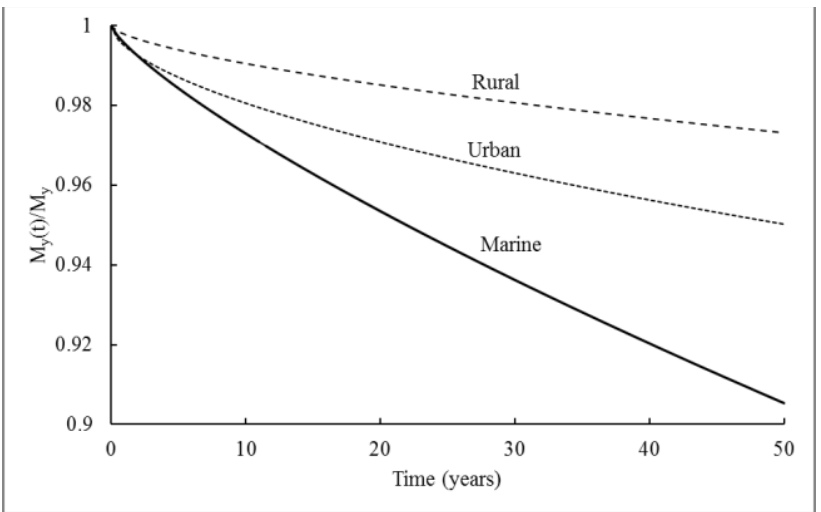

Figure 11. Prediction of deterioration of column base

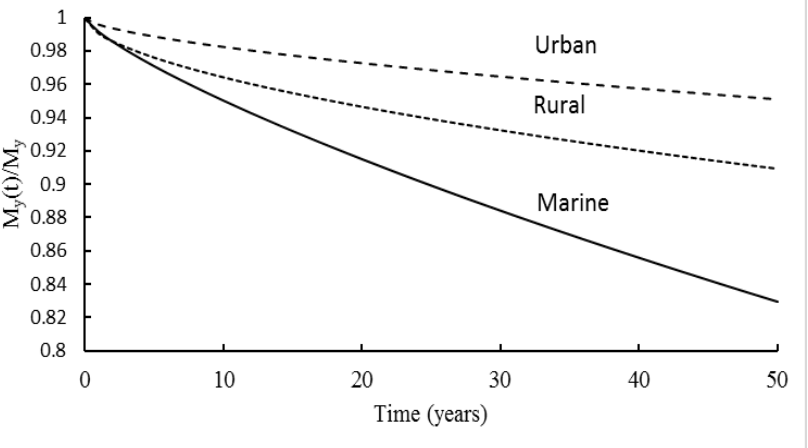

Figure 12. Prediction of dterioration of beam-column conection

TABLE IV. PARAMETERS IN (10), (11) AND (12)

\begin{tabular}{|c|c|c|c|c|c|}
\hline Parameter & a & b & c & d & e \\
\hline $\begin{array}{c}\text { Value } \\
(\mathrm{mm})\end{array}$ & 63 & 65 & 23 & 23 & 37 \\
\hline Parameter & $\mathbf{f}$ & $\mathbf{h}$ & \multicolumn{2}{|c|}{$\mathbf{f}_{\mathbf{y}}(\mathbf{M P a})$} & $\mathbf{T}_{\mathbf{f l}}$ \\
\hline $\begin{array}{c}\text { Value } \\
(\mathrm{mm})\end{array}$ & 72 & 275 & 91.43 & 17.3 \\
\hline
\end{tabular}

\section{CONCLUSION}

This paper proposes a new deterioration model (i.e. TDYMM), which is based on yield line theory and power corrosion rate model. Moment resistance of steel structural connection is expressed analytically as a function of time. The yield line model is compared to a non-linear FE analysis and good agreement. The proposed model could be applied as a practical tool to predict the corrosion-induced failure time of the column bases. Using the proposed model, strength of column base and beam-column connection over a period of 50 years and in three different exposure categories is presented.
A further study on the corroded structural steel members which originated from long-term natural exposure is being conducted to provide adequate statistical data. The further study is able to substantiate the newly proposed model.

\section{REFERENCES}

[1] P. Begley, "Anzac Bridge light pole crashes over footpath," in Sydney Morning Herald, ed, 2015.

[2] C. Li, W. Lawanwisut, and J. Zheng, "Time-dependent reliability method to assess the serviceability of corrosion-affected concrete structures," Journal of structural engineering, vol. 131, pp. 1674-1680, 2005.

[3] V. Sarveswaran, J. Smith, and D. Blockley, "Reliability of corrosiondamaged steel structures using interval probability theory," Structural Safety, vol. 20, pp. 237-255, 1998.

[4] R. Rahgozar, "Remaining capacity assessment of corrosion damaged beams using minimum curves," Journal of Constructional Steel Research, vol. 65, pp. 299-307, 2009.

[5] B. Hu, R. Chan, and C. Q. Li, "Remaining Capacity Assessment of Corrosion Damaged Column Bases," presented at the 4th International Conference on Sustainability Construction Materials and Technologies, Las Vegas, USA, 2016.

[6] K. W. Johansen, Yield-line theory: Cement and Concrete Association, 1962.

[7] X. L. Zhao, "Yield line mechanism analysis of steel members and connections," Progress in Structural Engineering and Materials, vol. 5, pp. 252-262, 2003.

[8] T. Murray and L. Shoemaker, "Design Guide 16: Flush and Extended Multiple-Row Moment End-Plate Connections," ed: American Institute of Steel Construction, 2002.

[9] H. Tagawa and S. Gurel, "Application of steel channels as stiffeners in bolted moment connections," Journal of Constructional Steel Research, vol. 61, pp. 1650-1671, 2005.

[10] A. Wheeler, M. Clarke, G. Hancock, and T. Murray, "Design model for bolted moment end plate connections joining rectangular hollow sections," Journal of Structural Engineering, vol. 124, pp. 164-173, 1998.

[11] T. Wierzbicki and J. Huang, "Initiation of plastic folding mechanism in crushed box columns," Thin-walled structures, vol. 13, pp. 115-143, 1992.

[12] P. Bhatt, T. J. MacGinley, and B. S. Choo, Reinforced Concrete Design to Eurocodes: Design Theory and Examples, Fourth Edition: Taylor \& Francis, 2014.

[13] A. H. Nilson, D. Darwin, and C. W. Dolan, Design of concrete structures: McGraw-Hill Higher Education, 2010.

[14] H. Townsend and J. Zoccola, "Eight-year atmospheric corrosion performance of weathering steel in industrial, rural, and marine environments," Atmospheric Corrosion of Metals, ASTM STP, vol. 767, pp. 45-59, 1982

[15] P. Albrecht and A. H. Naeemi, "Performance of weathering steel in bridges," NCHRP report, 1984.

[16] F. Akgül and D. M. Frangopol, "Lifetime performance analysis of existing steel girder bridge superstructures," Journal of Structural Engineering, vol. 130, pp. 1875-1888, 2004.

[17] ABAQUS, ABAQUS/Standard, User's Manual I-III, version 6.11: Hibbit,Karlsson and Sorenson, Inc., 2011.

[18] A. Standard, "Structural steel," in Hot-rolled bars and sections vol. AS/NZ 3679.1 :2016, ed, 2016. 